\title{
Schauer's Anti-Essentialism
}

\section{TORBEN SPAAK*}

Abstract. In his new book, The Force of Law, Frederick Schauer maintains that law has no necessary properties (a position he calls legal anti-essentialism), and that therefore jurisprudents should not assume that an inquiry into the nature of law has to be a search for such properties. I argue, however, that Schauer's attempt to show that legal anti-essentialism is a defensible position fails, because his one main argument (the cognitive science argument) is either irrelevant or else incomplete, depending on how one understands it, and because the other main argument (the family resemblance argument) is false.

\section{Introduction}

In his new book, The Force of Law (Schauer 2015), distinguished jurisprudent and first amendment scholar Frederick Schauer investigates the role of coercion in law. He maintains that coercion is a very important feature of law, because all known legal orders (or legal systems) are coercive and because coercion is very likely what actually motivates most people-officials as well as citizens-to obey the law. He argues, as regards the question of motivation, that once we substitute a distinction between self-motivated (or self-interested), law-motivated, and other-motivated or morally-motivated behavior for the cruder distinction between self-interested and law-motivated behavior employed by many scholars who have been considering our reasons for obeying the law, we will see that it is a mistake to believe that many people obey the law just because it is the law, and that the threat of coercion is very likely an important motivating factor. The reason why it is important to consider other-motivated and morally-motivated behavior is, of course, that such conformity to legal requirements does not qualify as law-motivated obedience.

But Schauer also has important things to say about jurisprudential methodology, maintaining as he does that jurisprudents should not follow H.L.A. Hart and others

\footnotetext{
* I would like to thank the participants in the workshop "The Force of Law. A Workshop with Fred Schauer" at Bocconi University, Milan on 2-3 October 2014, for helpful comments on my presentation of the ideas in this article. I would also like to thank the participants in the advanced seminar in practical philosophy, Uppsala University, especially Jens Johansson, for helpful comments on an earlier version of the article, and Åke Frändberg and Patricia Mindus for equally helpful comments on an even earlier version of the article. Finally, I would like to thank Robert Carroll for checking my English. As always, the responsibility for any remaining errors and imperfections in the article rests with the author alone.
} 
in assuming that an inquiry into the nature of law must be a search for essential properties of law (in order to qualify as an inquiry into the nature of law), but should instead focus on properties that are typical of law and important. He adduces two distinct claims in support of this main methodological claim (MMC), as I shall refer to it, namely, (1) that law has no essential properties, and (2) that focusing on essential properties of law to the exclusion of properties that are typical of law and important, albeit not essential, means that the theorist will run the risk of missing out on important insights. And he adduces in turn two distinct claims in support of claim (1), namely, (1a) that people in general think of and with concepts not in terms of necessary and sufficient conditions for their proper application, but in terms of central and peripheral cases, and accept that not all instances, not even all central instances, of a concept share any one property or properties, and (1b) that the concept of law is a family resemblance concept, or a so-called cluster concept.

I find both (MMC) and the claims (1)-(2), including the supporting claims (1a) and (1b), interesting and well worthy of extended discussion. Clearly, since jurisprudents focus on the question of the nature of law, they should know how to go about an inquiry into the nature of law, and how not to, and they should also know why they should go about such an inquiry in the one way rather than the other. Questions such as "What is an essential property?," "Do we have reason to believe that law has essential properties?," and "Assuming that law does have essential properties, should we focus our jurisprudential inquiries exclusively on those properties?" should be of considerable interest to any reasonably reflective jurisprudent.

But the role of (MMC) in Schauer's inquiry, as distinguished from its truth or defensibility, is also interesting, and in my view somewhat puzzling. Since no jurisprudent in his right mind would want to deny Schauer the right to investigate the role of coercion in law, but would probably only say that, strictly speaking, such an inquiry does not qualify as an inquiry into the nature of law, one may wonder why Schauer considers this question to be so important. Why does he want his investigation to qualify as an inquiry into the nature of law? Why does he not just go ahead and investigate the role of coercion in law and accept that some, perhaps quite a few, jurisprudents will not consider such an investigation to be an inquiry into the nature of law?

The answer to this question appears to be that Schauer wishes to undertake a philosophical investigation (or examination) of coercion in law:

Having shed the belief of supposing that properties that are not conceptually necessary are of little philosophical or jurisprudential interest, we are now better situated to think about those pervasive aspects of law that are ubiquitous and typical but not conceptually essential. Coercion is surely one of those aspects, and freed from the necessity of limiting our examination to conceptual essences we can recover the theoretical and philosophical examination of coercion in law from the exile to which a dubious essentialism has cast it. (Schauer 2015, 43)

I do not find this answer convincing, however. For, as Schauer $(2015,4-5)$ himself notes, and as is clear from his own book, an investigation of a legal phenomenon, such as legal coercion, may well be philosophical without amounting to an inquiry into the nature of law, as that enterprise has traditionally been conceived. 
Why, then, does Schauer want his philosophical investigation to qualify as an inquiry into the nature of law? Why does he not rest content knowing that his is a very interesting, philosophically inspired investigation of the role of coercion in law?

I shall not, however, pursue this (rather mild) objection to Schauer's analysis, but shall focus instead on Schauer's anti-essentialism and the above-mentioned two claims adduced by Schauer in support of it, namely, (1a) and (1b), and their relation to one another. I shall argue, more specifically, (i) that Schauer's attempt to show that legal anti-essentialism is a defensible position fails, because argument (1a) is either irrelevant or else incomplete, depending on how one understands it, and because argument (1b) is false, since the concept of law is not a family resemblance concept, and possibly also incoherent, (ii) that claims (1a) and (1b) could not be true together, and (iii) that Schauer's discussion of properties of law in the chapter on the differentiation of law is in tension with, and might even undermine, the legal anti-essentialism that Schauer espouses. I shall also argue (iv) that Schauer's legal anti-essentialism does not seem to be anti-essentialism in the usual sense of a rejection of the existence of essential properties, but rather a rejection of the possibility of analyzing the concept of law in terms of necessary and sufficient conditions, which is a different and quite radical view. Moreover, I shall argue (v) that legal anti-essentialism in Schauer's sense is a problematic doctrine, because it seems to render parts of legal scholarship, such as the interesting and valuable discipline of comparative law, ${ }^{1}$ more or less pointless, and (vi) that a jurisprudent who despite the objections set forth in this article accepts legal anti-essentialism (in Schauer's sense) should consider modifying his approach to the inquiry into the nature of law accordingly by giving up the method of philosophical analysis and trying instead either the method of explication or the method of the ideal-type. Finally, I shall argue (vii) that we do not have to go all the way back to the time of Bentham and Austin to find a prominent jurisprudent who puts coercion at the center of law, but can find a much more recent jurisprudent who does precisely that, namely Scandinavian realist Karl Olivecrona, and (viii) that a comparison of Schauer's and Olivecrona's accounts of legal coercion makes it clear that these accounts treat very different questions and differ quite a bit in general, and that the main reason why this is so is that they differ in their understanding of what an inquiry into the nature of law is.

I begin, however, by considering the structure of Schauer's argumentation (Section 2) and by saying a few words about how I understand the method of philosophical analysis, which Schauer objects to (Section 3). Having done that, I consider the claims (1a) and (1b) in more detail, including the logical relation between the two claims (Sections 4-8), discuss rather briefly two alternative methods of jurisprudential inquiry, namely the method of explication and the method of the ideal-type (Section 9), and identify a tension, perhaps even a contradiction, in Schauer's discussion of (what Schauer refers to as) the differentiation of law (Section 10). The article concludes, in an attempt to place Schauer's investigation in a larger context, with a brief consideration of Karl Olivecrona's thoughts on legal coercion (Section 11).

${ }^{1}$ For a valuable treatise on comparative law, see Zweigert and Kötz (1998). 


\section{The Structure of Schauer's Argumentation}

Schauer $(2015,2-3)$ observes that the received view among contemporary jurisprudents in the English-speaking world is that it is not in the nature of law to be coercive. He explains that the defenders of the received view argue in support of it (A) that we can conceive of law, including legal obligation, without coercion (ibid., 31-5), and (B) that as a matter of fact many citizens (Hart's so-called puzzled men) are quite willing to obey the law just because it is the law and that this means that the idea of non-coercive law plays an important role in our world (as distinguished from a merely possible world) (ibid., 41-8). Observing that (A) is a conceptual and (B) an empirical argument (ibid., 42), Schauer objects that (A) is irrelevant (ibid., chap. 3) and that (B) is false (ibid., chaps. 4-6). The picture below displays the structure of his argumentation concerning argument $(\mathrm{A})$ :

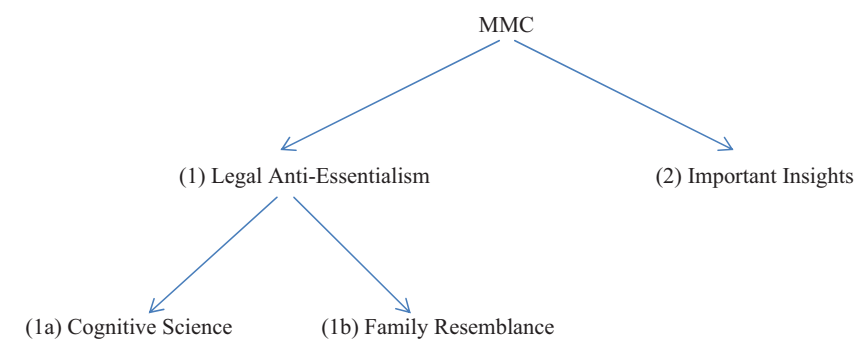

To show that (A) is irrelevant, Schauer defends (MMC), and to support (MMC) he adduces, as we have seen, claims (1) and (2), including the supporting claims (1a) and (1b). Let us consider these claims more closely, beginning with the first of the two supporting claims, namely, (1a). This is the claim that cognitive scientists have found that people in general think of and with concepts not in terms of necessary and sufficient conditions for their proper application, but in terms of central and peripheral cases, and accept that not all instances, not even all the central instances, of a concept share any one property or properties (ibid., 37-8).

As I shall explain, I am not convinced by this argument. Let us begin by noting that (1a) can be interpreted in at least three different ways. First, Schauer might simply mean that the fact that people in general think of and with concepts in the way explained gives jurisprudents a sufficient reason to reject the method of philosophical analysis, since philosophers should adopt the same approach as people in general to the analysis of concepts. But even if there is something wrong with analyzing concepts in terms of necessary and sufficient conditions, the problem cannot be that people in general do not do this. Even if people do think of and with concepts in terms of central and peripheral cases and accept that not all instances, not even all the central instances, of a concept need to share any one property or properties, they may be wrong to do so, or it may not be the only acceptable way of thinking of and with concepts. Thus conceived the argument is simply irrelevant, in that it has no bearing on the claim it is meant to support.

Another way to understand Schauer would be to assume that he is making the strong claim that the way people in general think of and with concepts constitutes, or in some looser way determines, the existence and properties of concepts, so that we 
can say of the relevant concepts (the ones that people in general concern themselves with), including the concept of law, that they are to be understood precisely in terms of central and peripheral cases in the way suggested. The main problem with this interpretation, however, is that Schauer does nothing to show that the practice of concept-users in general does constitute (or determine) the existence and properties of concepts. So the claim thus conceived is not only quite bold, but also incomplete.

Alternatively, we might take Schauer to be making the weaker claim that the best explanation of the fact that people in general think of and with concepts in the way described is that concepts are such that they are best understood in terms of central and peripheral instances. But the question, of course, is whether this really is the best explanation. And since we are not told why it would be the best explanation, I conclude that this claim (or this version of the claim), too, is incomplete.

(1b) The concept of law is a family resemblance concept, or a so-called cluster concept, which is to say that not all its instances, not even all its central instances, share any one property or properties (ibid., 38-9).

I am not, as I shall explain, convinced by this claim either. First, I simply do not believe that the concept of law is a family resemblance concept, or a cluster concept. Surely the various national legal orders, EU law, international law, and perhaps also so-called transnational law, share several properties, such as being sets or systems of norms that aim to regulate human behavior and claim supremacy in relation to other sets or systems of norms. Secondly, I have doubts about the coherence of family resemblance concepts in general, on the grounds that it is far too easy for an object or a property to satisfy the sufficient condition for falling under the family resemblance concept, namely, that of resembling the relevant phenomenon in some respect or another (on this, see Section 6). Thirdly, even if the concept of law were a family resemblance concept, the rational thing for a jurisprudent to do in light of this insight would not be to simply conclude that law is, as Schauer (ibid., 5) puts it, a "diverse [...] social phenomenon," but to attempt to explicate a fruitful concept of law, or perhaps adopt the method of the ideal-type (on this, see Section 9).

(2) We run the risk of missing out on important insights if we focus on essential properties of law to the exclusion of properties that, although not essential, are typical of law and important. As Schauer writes,

[1]aw might simply be too diverse a social phenomenon to support a unifying theory with very much explanatory power. Or even if a theory of the essence of law, or only of its necessary properties, were possible, such theories might turn out to be so abstract as to leave too many interesting questions, including philosophical questions, about law, about laws, and about legal systems unanswered. (Schauer 2015, 5)

I think Schauer is right on this count. But the reason, as I see it, is not that law is in some sense a diverse social phenomenon (as he suggests in the first sentence of the quotation), but that focusing on essential properties of law will unavoidably result in a very abstract account of law (as he suggests in the second sentence of the quotation), and that as a result we may well miss out on properties that, although not essential, are typical of law and important. Consider in this regard Raz's (1990, 157-61) claim that coercion is not an essential property of law, because we can imagine rational beings other than humans who are subject to a system of norms, and who have reason to obey these norms whether or not there are any sanctions (on this, see also Oberdiek 1976). Clearly, Raz's thought example is very abstract, 
and it seems to me that if we focus exclusively on properties of law that are present at this very high level of abstraction, we may well miss out on properties that, although not essential, are typical of law and important-such as coercion.

To show that the empirical claim-(B)-is false, Schauer (2015) points out that we have no empirical basis for believing that there are many puzzled persons in the world (ibid., 4-6). In reality, he points out, the existence of sanctions is quite important to the functioning of the legal machinery in most of the world, because it turns out that rather few people obey the law just because it is the law (ibid., chaps. 5-6). We see that this is so, he continues, once we substitute a distinction between (i) selfmotivated (or self-interested), (ii) law-motivated, and (iii) other-motivated or morallymotivated behavior for the cruder distinction between self-motivated and lawmotivated behavior employed by most scholars who have been concerned with the question of whether, and if so why, people obey the law (ibid., 48-54). For once we do, we will realize that behavior in keeping with legal requirements may be motivated by moral or other non-legal considerations that overlap only contingently with the relevant legal requirements. And to obey the law for contingently overlapping moral or other non-legal reasons is not to obey the law just because it is the law. Hence morally-motivated and other-motivated behavior in accordance with the law should not be thought of as law-motivated behavior, and this in turns means that we have no good reason to believe that there are many puzzled persons (in Hart's sense) around.

In what follows, I shall focus on Schauer's discussion of the conceptual claim, (A), that we can conceive of law, including legal obligation, without coercion. The reason is that I find it especially interesting, involving as it does not only the interesting claim (MMC), but also the intriguing claim (1) - that law has no essential properties-and the two supporting claims (1a) and (1b).

\section{Philosophical Analysis}

Schauer does not say much about the method of philosophical analysis that he attacks, and I should therefore like to briefly consider this method, as I understand it. My aim in doing so is to be as clear as possible about the target of Schauer's criticism.

It appears that at least some contemporary jurisprudents hold that to inquire into the nature of law is to search for essential properties of law (see, e.g., Dickson 2001, 15-20; Raz 2009, 24-6). ${ }^{2}$ To say that a property, $p$ (say, coerciveness), is an essential property of an object, $O$ (say, law), is to say that $p$ is a necessary property of $O$, that $O$ has $p$ in all possible worlds where $O$ exists, so that if it turned out that $O$ lacked $p$ in one or more possible worlds, $p$ would not be an essential property of $O$. We should also assume that an object may well share an essential property with other objects, in the way that Fido the poodle shares the property of being a dog with Brutus the dachshund. That is to say, we should not insist that an essential property, $p$, be a property that is unique to $O$, such as, say, the property of $O$ of being identical to $O$. For it is clear that most alleged essential properties of law, such as normativity or coerciveness, are not unique to law. (On essentialism, see, e.g., Lowe 2002, 96-9).

2 But although they certainly speak of "essential" properties of law, they might for all I know have in mind only "necessary" properties of law in the way to be explained below. I shall, however, have to leave it an open question what, exactly, they have in mind. 
Now one (but not the only) way of understanding the enterprise of inquiring into the nature of law is to conceive of it as an analysis of the concept of law (see, e.g., Alexy 2008; Hart 1961, chap. 1; Raz 2009, 18-24). On what I shall refer to as the classical conception of conceptual analysis (Langford 1942; McGinn 2012, 4-5, 14; Sosa 1983), the analysis of a concept aims to establish an analytically true equivalence between analysandum (that which is to be analyzed) and analysans (that which does the analyzing). That is to say, the task of the analyst is to find properties that are individually necessary and jointly sufficient for $X$ to qualify as law, and that the type of necessity involved is that of conceptual (or logical)—as distinguished from metaphysical, or "natural," or some other type of-necessity. ${ }^{3}$

Note here that to speak of necessary and sufficient conditions for the applicability of a concept, such as the concept of law, as Schauer does, ${ }^{4}$ is not necessarily to assume the existence of essential properties in the sense explained above. Thus one may well maintain that an object, $O$, satisfies both necessary and sufficient conditions for being law, while rejecting the view that the properties that correspond to these necessary (and sufficient) conditions are essential properties of $O$. For example, one might argue that an object, $O$, is a legal order if, and only if, $O$ satisfies the conditions $p, q$, and $r$, without also having to hold that $p, q$, and $r$ are essential properties of $O$-there might be a possible world in which $O$ lacks one or more of these properties.

The question is whether one can conceive of a possible world in which $O$ exists but lacks one or more of the relevant properties. Here difficulties may arise. For example, whereas Jones might argue that $p$ is not an essential property of $O$, since (as he sees it) $O$ clearly exists without $p$ in a possible world, $w_{2}$, Smith might object that $p$ is indeed an essential property of $O$, since (as she sees it) $O$ does not at all exist in $w_{2}$. For, as Smith sees it, $O$ simply would not be $O$, if $O$ lacked $p$. What this means, then, is that Smith would refuse to recognize the existence of $O$ without $p$ in $w_{2}$ as a counter-example to her claim that $p$ is an essential property of $O$.

Smith and Jones might, however, agree that $O$ clearly exists without $q$ in $w_{3}$ (where $q$ is the somewhat banal property of having more than 25,000 legal norms), which means that they would agree that $q$ is not an essential property of $O$. The reason for this agreement would simply be that unlike $p, q$ is such a banal property that neither Smith nor Jones would be tempted to object that $O$ without $q$ would no longer be $O$.

Moreover, Smith and Jones might disagree about the essential properties not of $O$, but of the concept that $O$ falls under, that is, the concept of a legal order. What properties might these be? To begin with, the properties of the concept of a legal order will be different from the properties of an instance of the concept of a legal order-concepts, including the concept of a legal order, are very different entities from legal orders. For example, the concept of a legal order does not (and cannot reasonably) have the properties of being a system of norms or of being coercive.

\footnotetext{
${ }^{3}$ Note that Jackson $(1998,67-86)$ rejects the distinction between conceptual and metaphysical necessity (or possibility), arguing that it is the same type of necessity in both cases and that the only difference between conceptual and metaphysical necessity (or possibility) is to be found on the epistemological level.

4 Actually, Schauer speaks for the most part only of necessary (or essential) conditions and mentions sufficient conditions only a couple of times. See, e.g., Schauer 2015, 3-4, 37-41.
} 
If the concept of a legal order has essential properties at all, they must be properties such as that of being a concept or being composed of certain other concepts, such as the concept of a system of norms or the concept of being coercive, and so on.

The question of the essential properties, if any, of a concept is a difficult one. The important point for our purposes, however, is that the question of the essential properties of a concept is different from the question of the essential properties of an instance of that concept, and that both these questions are different from the question of which are the necessary and sufficient conditions for an object, $O$, to qualify as an instance of the concept.

Essentialism is thus not without its problems. The reason why one might nevertheless want to embrace essentialism is that one might believe that doing so would help justify a given analysis of a concept. For example, one might defend an analysis of the concept of law, according to which law necessarily raises a claim to correctness (Alexy 2002, 35-40), on the grounds that one considers (on the basis of a thought experiment) the property in question, call it $c$, to be an essential property of law, in the sense that law has $c$ in all possible worlds-if what purports to be law did not have $c$ in a certain possible world, then $c$ would not be an essential property of law or else what purports to be law would not be law. If, on the other hand, one did not consider $c$ to be an essential property of law, one would need some other reason to defend the analysis, perhaps by reference to ordinary or expert usage.

The distinction between the satisfaction of necessary (and sufficient) conditions for the applicability of a concept, on the one hand, and the question of the essential properties, if any, of the object (or property) that satisfies the necessary (and sufficient) condition(s), and the question of the essential properties, if any, of the relevant concept, on the other hand, is of interest in this context, because when Schauer speaks of "essential" properties of law, he appears to have in mind not essential properties of law in either of the two senses explained, but rather properties that correspond to the necessary (and sufficient) conditions for the applicability of the concept of law. And this in turn appears to mean that Schauer's legal antiessentialism (to be discussed below in Section 4) is not anti-essentialism in the sense of a rejection of the existence of essential properties of an instance of the concept of law or of the concept of law itself, but anti-essentialism in the sense of a rejection of the possibility of analyzing the concept of law in terms of necessary and sufficient conditions. ${ }^{5}$ This is quite a radical stance, and it is not what is usually meant by the term "anti-essentialism."

Generally speaking, the distinction between philosophical analysis and the two versions of essentialism may also be of interest, because the theorist might be rejecting the possibility of philosophical analysis because he is confusing it with one or the other version of essentialism. It is not, however, clear to me that Schauer is guilty of this type of confusion.

In any case, focusing on the concept of $X$ rather than on $X$ itself may be an advantage, in the sense that one avoids taking for granted that there is something that corresponds to the concept. For example, it seems advisable to focus on the concept of a witch or the concept of a unicorn, while leaving it an open question

\footnotetext{
${ }^{5}$ Although Schauer is not explicit on this, I assume that he also rejects the existence of essential properties of law in the sense explained-if he did not, he would likely (but not necessarily) believe in philosophical analysis.
} 
whether there are in fact witches or unicorns. As Strawson $(1992,33)$ puts it: "By talking about our conceptual structure, the structure of our thought about the world, rather than, as it were, directly about the world, we keep a firmer grasp of our own philosophical procedure, a clearer understanding of what we are about."

But what is a concept? Some conceive of concepts as psychological entities, viz. mental representations, others conceive of them as abilities, and yet others conceive of them as meanings, specifically Fregean senses (on this, see Margolis and Laurence 2014, sec. 1). I shall assume in what follows that a concept is the meaning, or at least part of the meaning, of a word or an expression, specifically its Fregean sense (Sinn) (Frege 1980; Miller 2007, chap. 2). I shall also assume that a word or an expression, such as "law" or "Recht," may express the same concept as another word or expression in the same or in a different language. And if a word or expression is ambiguous, if it has more than one sense, then it simply expresses more than one concept. Moreover, the sense (or intension) of a word or an expression determines its extension, that is, the class of (abstract or concrete) entities (or properties) to which the word applies. On this analysis, then, the concept of law determines the existence of law in the sense that $X$ will qualify as law if, and only if, $X$ meets the criteria laid down in the concept of law.

However, not everyone agrees that an inquiry into the nature of law should be conceived as an analysis of the concept of law. Moore (2000, 309-11), for example, objects to the habit among contemporary jurisprudents of focusing on the concept of law rather than on law itself. He locates the problem in the acceptance by jurisprudents of a conventionalist theory of meaning, such as the one crudely sketched above, according to which a word, such as "law," refers to the object, law, via a concept, "law." Moore embraces instead a theory of direct reference, according to which a word refers directly to the object (or property) in question without help of a concept (on this type of theory, see Platts 1997, chap. 12). Thus, on this analysis, the word "law" gets its meaning by virtue of referring to the object, law, and there will simply be no concept of law (with a more or less complex and interesting structure) that the analyst can sink his teeth into (on this topic, see McGinn 2012, 107-8).

I shall not go into the difficulties that surround one's choice of a theory of meaning, but shall be content to point out that the application of a theory of direct reference to a field in which most of the objects or properties referred to are artificial rather than natural (such as gold, water, tiger, and so on) is problematic (on this, see Coleman and Simchen 2003, 14-5). To say that legal terms, such as "law," "legal order," "jurisdiction," "locus standi," "separation of powers," "judicial review," "plain meaning," "predictability," "analogical application," "contra legem decision," "legislative intent," "legal right," "legal power," or "legal validity" refer to entities or properties that are natural kinds simply does not seem plausible: while natural kinds may be found in nature, they are hardly found in law. ${ }^{6}$

In any case, to test a proposed analysis, the analyst is to invoke so-called intuitions about the correct application of the concept to various test cases and consider

${ }^{6}$ To be sure, Moore $(2000,311)$ does not maintain that law is a natural kind, but proposes instead that it is a functional kind, that is, a kind that fulfills a certain function, and that the term "law" gets its meaning because it refers (without a conceptual intermediary) to this functional kind. But this view is quite problematic, presupposing as it does that law has one (and only one) necessary function. On this, see Hart (1994, 248-9). 
whether the analysis is in keeping with these intuitions (on this, see Jackson 1998, 28-37). Would $X$ be a legal order? Would $Y$ be a case of discrimination? Would $Z$ be an instance of knowledge? These intuitions are understood to be accessible to the analyst a priori and only a priori, that is, independently of experience, and this means that conceptual analysis is understood to be independent of a posteriori knowledge and logically prior to any empirical investigations into the relevant subject matter, and thus immune to empirical falsification.

A much-discussed example of conceptual analysis in the field of jurisprudence is to be found in Robert Alexy's well-known argument from correctness (Alexy 2002, 35-40). To substantiate his claim that law necessarily raises a claim to correctness (that has a moral content), Alexy asks the reader to consider a hypothetical constitutional article $(C A)$, according to which $X$ is a federal, democratic, and unjust republic, and points out that $(C A)$ is absurd. And he explains that the absurdity is due not to a technical, moral, or conventional fault, but to (what he calls) a performative contradiction. His idea is that $(C A)$ is absurd because the act of legislation necessarily involves the raising of a claim to correctness, and because the claim to correctness is contradicted by the content of $(C A)$. To enact $(C A)$, then, is to make a conceptual mistake (in a broad sense that includes performative contradictions) (ibid., 37-8). So, as Alexy sees it, it is the necessary existence of the claim to correctness that explains the absurdity of $(C A)$.

Conceptual analysis is, however, a somewhat problematic enterprise. First, the idea that an analysis aims to establish an analytically true equivalence between analysandum and analysans presupposes that we can distinguish between analytic and synthetic statements (or sentences), that is, between statements that are and statements that are not true in virtue of their meaning. However, philosophers such as Quine (1953) and Harman (1999) have objected that this distinction cannot be upheld, so that there will be no sharp distinction between conceptual analysis and empirical investigations, and that therefore conceptual claims will not be logically independent of empirical claims (see also Leiter 2007, 131-5. For criticism, see Grice and McGinn 2012, chap. 7; Searle 1969, 5-12; Strawson 1956).

I am not sure what to think of the details of Quine's critique and shall be content to say here that it certainly seems to me that it is possible to make a distinction between claims that are true in virtue of their meaning and claims that are not, and to make a distinction between conceptual and empirical claims. While Quine may be right that there is in principle no unambiguous criterion that we can use to tell the difference between analytical and synthetic claims, I am inclined to hold that, at the very least, the distinction in question makes sense.

Secondly, there is the so-called paradox of analysis (on this, see, e.g., Aqvist 1962; Carnap 1956, 63-4; Langford 1942, 322-3; McGinn 2012, chap. 4; Miller 2007, 46-7; Moore 1942, 660-7), according to which any analysis will either be trivially correct and thus uninformative, or else incorrect. Here is Langford's description of the paradox:

Let us call what is to be analyzed the analysandum, and let us call that which does the analyzing the analysans. The analysis then states an appropriate relation of equivalence between the analysandum and the analysans. And the paradox of analysis is to the effect that, if the verbal expression representing the analysandum has the same meaning as the verbal expression representing the analysans, the analysis states a bare identity and is trivial; but if the two verbal expressions do not have the same meaning, the analysis is incorrect. (Langford 1942, 323) 
The basic assumptions here, as I understand it, are (i) that an analysis aims to establish an analytically true equivalence between analysandum and analysans, (ii) that analytical statements are true in virtue of their meaning, (iii) that a successful analysis will make it clear that the two expressions representing the analysans and the analysandum, respectively, have the same meaning, or, if you will, express the same concept, and (iv) that we have immediate access to the meaning of the words in our language. And this appears to mean that a correct analysis cannot provide the analyst with any information that he did not already have by virtue of simply understanding the meaning of the relevant expressions. If, on the other hand, the analysandum and the analysans do not have the same meaning, if they do not express the same concept, the analysis will be incorrect.

I am not, however, too worried about the paradox of analysis. As McGinn (2012, 57-60) explains, the paradox trades on an equivocation of the term "know," namely the equivocation between explicit and implicit knowledge (see also Smith 1994, 378). More specifically, the analysans of an analysis provides an explicit formulation of the concept that occurs in the analysandum, the content of which the analyst (and others) may well have grasped implicitly. For it is clearly possible to use concepts such as "law,' 'right,' 'knowledge," or "inference" reasonably competently without being able to state in precise terms an analysis of any of them.

Precisely because one knows how to speak of law or of knowledge, and so on, one is able to assess the adequacy of a proposed analysis of the concept of law, the concept of knowledge, and so on. This means that an analysis of a concept that respects the requirement of sameness of meaning, can be informative, in the sense that it provides us with explicit (or theoretical) knowledge that goes beyond the implicit (or practical) knowledge that we already had.

Thirdly, Dworkin $(1986,31-44)$ has objected that theorists who purport to analyze the concept of law are necessarily engaged in a purely semantic enterprise, namely, that of clarifying the meaning of the word "law," and that this means that such an enterprise fails to treat the inquiry into the nature of law as a substantive enterprise, that is, an investigation of law itself. But although such a characterization of the enterprise of conceptual analysis is not completely unwarranted, it is nevertheless misleading. To begin with, an analysis of the concept of law, say, will contain much more information than one could possibly squeeze into the meaning of the word "law." As Hart $(1961,16)$ points out, "nothing concise enough to be recognized as a definition could provide a satisfactory answer to it [the question, 'What is law?'] The underlying issues are too different from each other and too fundamental to be capable of this sort of resolution." For example, although he believes that the concept of law is to be analyzed in terms of the concept of a union of primary and secondary rules, he clearly does not believe that the idea of a union of primary and secondary rules is part of the meaning of "law." For, he points out (ibid., 79), we shall not assume that we will find such a union of primary and secondary rules whenever the word "law" is properly used.

That an analysis of a concept, such as the concept of law, will typically contain much more information than one could possibly squeeze into the meaning of the word or words that express the concept, such as "law," is clear from a quick glance at the dictionary. For example, the Concise Oxford Dictionary (7th ed., 1982) offers, inter alia, the following account of the meaning of "law": "body of enacted or customary rules recognized by a community as binding"; the Swedish publication 
Bonniers svenska ordbok (8th revised ed., 2002) gives the following account of the meaning of the word "rättsstat" [law-state, Rechtsstaat]: "a state where there are guarantees that the organs of the state follow the laws" (my translation); and another Swedish publication, Norstedts svenska synonymordbok (4th ed., 1992), renders the meaning of the word "right" (in Swedish: "rättighet") as follows: "permission, license, power, privilege, prerogative, liberty" (my translation). Clearly, the meaning of words such as "law," "Rechtsstaat," "right," and other legal terms offered even by authoritative dictionaries cannot compete with the penetrating analyses put forward by philosophers or jurisprudents and other legal scholars; and, as I see it, this means precisely that much of the philosophical analysis of a concept, $C$, never finds its way into the meaning of the word or words that express $C$.

Moreover, and conversely, the meaning of words in general, including "knowledge" and "law," typically goes beyond the concept expressed by the word. For words get their meaning not only from the corresponding concept, but also in other ways. As Hart $(1961,79)$ puts it, "it is clear that the diverse range of cases of which the word 'law' is used are not linked by any such simple uniformity, but by less direct relations - often of analogy of either form or content-to a central case."

To be sure, there may seem to be a rather fine line between (i) giving necessary and sufficient conditions for a person to know something, or for there to be law, and (ii) accounting for the meaning of the words "knowledge" or "law," especially if one also thinks of a concept as (at least part of) the meaning of a word. For it may seem that in giving necessary and sufficient conditions for the application of the concept of knowledge, say, one is also explaining precisely when it is appropriate to use the word "knowledge." But, as I have said, things are not that simple. Not only will a competent analysis of a concept provide us with much more information than could possibly be squeezed into the corresponding word or words, words also get their meaning in other ways than from the concept they express.

It is worth noting, finally, that the distinction between clarifying the meaning of a word and investigating the object (or property) that the word refers to is reminiscent of, perhaps even identical to, the old distinction between nominal and real definitions (on such definitions, see Gupta 2014, 3-5; Robinson 1954). Adopting this terminology, we might say that Dworkin's position is that contemporary jurisprudents are concerned with nominal definitions when they really should be aiming for real definitions. ${ }^{7}$ My own position, then, is that contemporary jurisprudents are and should be concerned precisely with real definitions. As Gupta $(2014,5)$ puts it, "the philosophical quest for definition [or analysis] can sometimes fruitfully be characterized as a search for an explanation of meaning. But the sense of 'explanation of meaning' here is very different from the sense in which a dictionary or an ostensive definition explains the meaning of a word."

Fourthly, the very idea of a priori knowledge in the shape of intuitions is problematic. For different persons sometimes, perhaps often, have different and conflicting intuitions, and there appears to be no reliable method for determining which intuitions are to be trusted and which are not (on this, see e.g., DePaul and Ramsey 1998; Harman 1999; Leiter 2007). Indeed, as I see it, this is the problem with Alexy's analysis, mentioned above. Whereas some, such as myself, are

7 My guess, however, is that Dworkin would object to any talk of "definitions" in this context. 
inclined to accept the claim that $(C A)$ is absurd for conceptual reasons, others disagree and argue that although $(C A)$ is odd, this has nothing to do with the concept of law (Bulygin 1993, 2000).

Schauer does not, however, consider any of these well-known difficulties with the method of philosophical (or conceptual) analysis, but focuses instead on the above-mentioned claims (1a), (1b), and (2). I consider (1a) and (1b) in Sections 4-8 and reject them both.

\section{Schauer's Anti-Essentialism}

As we have seen, Schauer's legal anti-essentialism-that is, the claim that it is impossible to analyze the concept of law in terms of necessary and sufficient conditions-depends on what I (but perhaps not Schauer) take to be two distinct claims, namely (1a) that people in general think of and with concepts not in terms of necessary and sufficient conditions for their proper application, but in terms of central and peripheral instances, and accept that not all instances, not even all the central instances, of a concept share any one property or properties, and (1b) that the concept of law is a family resemblance concept, or a cluster concept, which means that not even all the central instances of the concept share any one property or properties (Schauer 2015, 37-41). As we have also seen (in Section 1), Schauer reasons that his anti-essentialism removes a methodological obstacle to jurisprudential focus on the property of legal coercion by making it clear that there are no essential properties of law to be had. For if there are no essential properties of law, the circumstance that coercion is not an essential property of law is neither here nor there, and this in turn means that the jurisprudential ground is cleared, as it were, so that the jurisprudent may focus, as Schauer thinks he should, on properties that, although not essential, are typical of law and important. As Schauer (ibid., 40) puts it, "[i]f the concept of law, or the proper application of the word 'law,' are best characterized in such an anti-essentialist way, or if the phenomenon of law simply has no essence, then the absence of coercion in things properly or at least plausibly understood as law is no longer fatal to coercion being an important feature of the central case of law."

But, as we have seen (in Section 3), although Schauer speaks of "essential" properties of law and of (legal) "anti-essentialism," he appears to have in mind not essential properties in the sense explained earlier, but rather properties that correspond to the necessary (and sufficient) conditions for the applicability of the concept of law. So, as I understand it, his legal anti-essentialism involves first and foremost a rejection of the possibility of analyzing the concept of law in terms of necessary and sufficient conditions for the applicability of the concept of law and, indirectly, a rejection of the existence of essential properties of law. What this means is that when Schauer claims that his legal anti-essentialism removes a methodological obstacle to his investigation, he means to say that since there are no shared properties of even all the central instances of the concept of law, the very enterprise of analyzing the concept of law in terms of necessary and sufficient conditions is doomed, and that jurisprudents can therefore in good conscience focus on properties that, although neither necessary nor sufficient for the applicability of the concept of law, are typical of law and important. 
At any rate, claims (1a) and (1b) are two distinct, albeit similar, claims. As I see it, (1a) is an empirical claim about the way people in general think of and with concepts and (1b) is either an empirical claim about the properties of certain concepts, or else a conceptual claim about the nature of concepts. I begin with (1a) and then turn to consider (1b).

\section{The Argument from Cognitive Science}

Schauer explains that cognitive scientists have found that people in general do not think of concepts in terms of necessary and sufficient conditions for their proper application, but in terms of central and peripheral cases, and accept that not even all the central cases of a concept share any one property or properties:

Cognitive scientists who study concept formation have almost universally concluded that people do not use concepts in the way that the "essential feature" view of concepts supposes. Rather, they understand that their concepts have central cases-flying birds, wine made from grapes, clever mathematicians-and also cases that are peripheral, such as non-flying birds, pineapple wine, and stupid mathematicians. /.../ Moreover, people think of concepts and categories in terms of properties-like flying for birds and grape origin for wine-that may not hold even for all of the central cases of the category. (Schauer 2015, 37. Footnotes omitted.)

He adds that the central idea in the research field known as generics is precisely that in many fields there are claims that are accepted as being generally true while tolerating exceptions. As he puts it, "[i]t ... appears that an important feature of human cognition and human communication is the use of probabilistically but not universally true characterizations as a vital part of our cognitive and communicative existence" (ibid., 39).

Schauer admits that the general anti-essentialist claim-that it is impossible to analyze concepts in terms of necessary and sufficient conditions-is itself contested, but he is content to have made plausible that this claim has more empirical support than the competing claim put forward by the defenders of philosophical analysis, namely, that many phenomena that are of interest to philosophers (law, right, obligation, knowledge, truth, meaning, intention, consciousness, cause, etc.) can be understood in terms of necessary and sufficient conditions for the applicability of the relevant concept:

The issue is not whether there are core and fringe cases of law, just as there are core and fringe cases of pretty much everything else. Rather, the question is whether even the core or standard or central cases can be understood in terms of necessary features. Many theorists say that they can, but many others say that they cannot, and the latter view-that even standard or central cases do not have essential properties-has its own substantial philosophical provenance and even more substantial empirical support. (ibid., 39)

I find the picture Schauer paints of the way people in general use concepts persuasive. It is my impression, too, that people in general do not usually think of and with concepts in terms of necessary and sufficient conditions for their proper application, and, indeed, that they do not care much for conceptual questions at all, but consider them to be "semantic" questions, which have little or nothing to do with real issues. As far as I can tell, they are quite content to be able to identify central instances of 
whatever concept is at issue and are happy to leave the peripheral instances for another day, thinking perhaps that only academics would worry about whether, say, a bike without a handlebar and saddle would be a faulty bike or no bike at all, or whether a will without a signature would be an invalid will or no will at all. ${ }^{8} \mathrm{I}$ am less sure whether people in general also accept that not even all the central instances of a concept share any one property or properties. I shall, however, accept the findings of the cognitive scientists for the purposes of this article.

My own view, however, is that people in general are wrong on this count. In some cases, we do have reason to concern ourselves with conceptual questions. If we neglect such questions, we will not be able to discuss legal, moral, political, philosophical, and many other kinds of question with sufficient precision. For example, to speak in a meaningful way of human rights violations, we need to have a reasonably clear understanding of what a human right is, that is, of the structure and content of the concept of a human right.

The important question in this context, however, is how we are to assess the claim under consideration, that is, claim (1a). Since the claim is that there are no necessary conditions for the applicability of many concepts, the claim must reasonably be a relevant objection to the method of philosophical analysis. Indeed, it seems to me that if we find the claim persuasive, we must as jurisprudents either change our understanding of what philosophical analysis is, or else give up the very approach to the question of the nature of law that involves laying down necessary and sufficient conditions.

I have serious doubts about the claim, however. As we have seen, we can distinguish at least three different interpretations of the claim. First, we might take Schauer to mean that the fact that people in general think of and with concepts in the way explained gives jurisprudents a sufficient reason to reject the method of philosophical analysis. But, one wonders, what does the way people in general think of and with concepts have to do with the existence and properties of concepts and the instances of concepts? I mean, the method of philosophical analysis obviously does not depend on the assumption that people in general do think of and with concepts in terms of necessary and sufficient conditions for their proper application, but on the much weaker assumption that such thinking is possible. So, on this interpretation, claim (1a) is irrelevant.

But, as I have said, perhaps Schauer means to say instead that the way people think of and with concepts actually constitutes (or in some looser sense determines) the existence and properties of the concepts in question, so that the fact (if it is a fact) that people in general do think of and with concepts in terms of central and peripheral instances and accept that not even all the central instances share any one property or properties means that not all concepts, not even all the central instances of concepts, share any one property or properties, and that therefore any attempt to lay down necessary and sufficient conditions for the applicability of a concept is doomed from the outset. If this is what he means, his claim is certainly relevant to the question of the defensibility of the method of philosophical, or conceptual, analysis.

\footnotetext{
8 The distinction between (i) a legally invalid statute and (ii) a statute that completely lacks legal character is well known in German legal scholarship and plays an important role in Gustav Radbruch's legal philosophy. See, e.g., Radbruch $(2006,7)$. I discuss Radbruch's distinction briefly in Spaak $(2009 b, 272-3)$.
} 
But thus conceived, the claim is quite problematic. For not only is the claim quite strong and, in my view, implausible, ${ }^{9}$ Schauer is not explicit that he does believe that the existence and properties of concepts depend on the practice of conceptusers in general or their view of concepts, still less does he explain what this relation of dependence looks like, if it exists. Does he mean to say, for example, that there can be no concepts over and above the concepts that are currently in use, or that the concepts that do exist can have no other properties than the ones that correspond to the views of the concept-users? Or does he mean to say, rather, that only some concepts depend in these ways on the practice of concept-users? Unfortunately, Schauer does not consider these (or similar) questions in his book. Since we have no answer to these (or similar) questions, we must conclude that, on this interpretation, Schauer's cognitive science claim, although relevant, is incomplete and needs to be fleshed out.

Alternatively, as we have seen, Schauer might be content to make the weaker claim that the best explanation of the fact that people in general hold this view is that concepts do in fact have these properties. One may, however, wonder whether the best explanation of this fact about concept-users really is that concepts have these properties. Since Schauer does not explain why this would be the best explanation, and since I can see no good reason to think that it is the best explanation, I do not find this alternative interpretation of Schauer's text convincing.

\section{The Family Resemblance Argument}

Schauer proceeds to point out that the same anti-essentialist idea has been recognized in several different philosophical traditions, perhaps most famously by Ludwig Wittgenstein, who (is said to have) introduced the idea of family resemblance into philosophical thinking:

Using the example of games, he [Wittgenstein] suggested that all the things we call games do not share common characteristics. There are no necessary or essential properties of games. And, importantly, there are no necessary or essential properties of all of the games we think of as central cases of games. It is not, or at least it was not for Wittgenstein and his followers, that there were central or prototypical or paradigmatic instances of games, such that we could identify the essential features of the paradigmatic cases-the things that made them paradigms-while recognizing that there were fringe or debatable cases that possessed some but not all of the properties of the paradigm. Rather, the things we call games, and even the multiple things that are central or paradigmatic cases of games, relate to each other as a family resemblance, like the strands of a rope rather than the links of a chain. Anything we understand as a game-as an instance of the concept of a game-shares some number of properties with some number of other games, but there are no properties that are shared by all games, not even by all of the games that are clear cases of games. (Schauer 2015, 38. Footnote omitted.)

I take it that the idea is that if the concept of $X$ covers, inter alia, the objects $A-D$, then $A$ may share one or two properties (say, i, ii) with $B$, which may share another property (iii) with $C$, which may share yet another property (iv) with $D$, which

\footnotetext{
${ }^{9}$ For example, it seems that if concepts depended in this strong way on human beings, we could not coherently maintain that there may be concepts that we will never acquire.
} 
may have no property in common with $A$, where the properties in question are such that if they were present, they would distinguish $X$ from other phenomena. ${ }^{10}$ That is to say, the objects (or properties) covered by the concept in question need have nothing in common, or, if you will, there are no necessary conditions for being an object (or a property) of the relevant kind. As Wittgenstein (1968, sec. 66) puts it, "we see a complicated network of similarities overlapping and crisscrossing: sometimes overall similarities, sometimes similarities of detail." And he (Wittgenstein) urges us, in keeping with this, not just to assume that all the things we refer to by a certain word have any one feature in common, but to look and see if this is really so (ibid., sec. 66): "For if you look at them you will not see something that is common to all, but similarities, relationships, and a whole series of them at that. To repeat: don't think, but look!"11

The property of family resemblance must not, of course, be confused with the property of ambiguity, that a word may have two or more different meanings (senses)-if a word is to qualify as a family resemblance word, there has to be a certain similarity (a family resemblance) between the instances that the word is used to refer to. For example, the English word "bank" is ambiguous in that it can mean (at least) "river bank" or "savings bank." But this has nothing to do with family resemblance. For the two instances-river banks and savings banks-are not related to each other in the way of family resemblance, but appear to have no relation at all to each other. The word "game," on the other hand, as we have just seen, is said to refer to a number of different objects (or phenomena) that resemble one another in some ways, but not in other ways, and (if Wittgenstein and Schauer are right) have no one property or properties in common.

Wittgenstein and Schauer thus maintain that there are at least some family resemblance words (or concepts) in English (and other natural languages), and other writers have maintained that there are plenty of such words (or concepts) around. But are Wittgenstein and Schauer right? I doubt it. McGinn (2012, chap. 2) objects that Wittgenstein failed to show that there are more than a few concepts that lack necessary and non-trivial conditions, or even that the concept of a game itself is a family resemblance concept (ibid., 15-21). ${ }^{12}$ Thus he points out that, on Wittgenstein's analysis, it is a necessary condition for $X$ to be a game that $X$ has "a family resemblance to things called 'games'" (ibid., 18), and that we may invoke the concept of probability and say that $X$ is a game if, and only if, $X$ "is more likely to have such features as competition, amusement, and winning and losing, than other types of human activity" (ibid., 20). He also points out that Bernard Suits

${ }^{10}$ I have added the qualification "where the properties in question are such that if they were present, they would distinguish $X$ from other phenomena" to make it clear that Schauer (quite reasonably) has in mind a rather narrow category of possible properties of law, which excludes trivial properties, such as the property of law of being identical with itself or, perhaps, of being an immaterial object.

11 On this general theme, see also Wittgenstein (1960, 17-20).

${ }^{12} \operatorname{Raz}(2009,29)$, too, doubts whether there are many concepts of the family resemblance kind: "While the meaning of many terms in natural languages cannot be given by a set of properties essential to their application, they usually have a core meaning with a structured set of extensions." 
actually succeeded in producing an analysis of the concept of a game in terms of necessary and sufficient conditions (ibid., 21-8). ${ }^{13}$

Moreover, McGinn points out that the very idea of a family resemblance concept may actually be incoherent. The problem, he explains (ibid., 28-9), is that the idea of family resemblance is just too permissive, in that it is far too easy for an object or a property to satisfy the sufficient condition for falling under a family resemblance concept, namely, that of resembling the relevant phenomenon (game, social institution, profession, etc.) in some respect or other. For example, the activity involving a policeman chasing a thief may well resemble a 100-meter race in one or two respects, though it certainly is not a game, but a matter of serious work on the part of the policeman (and the thief)-if the policeman could catch the thief without having to run so hard, he would of course do so. Indeed, says McGinn (ibid., 30), since everything bears some sort of resemblance to everything else, there is a distinct risk that, on Wittgenstein's analysis, we may end up with only one concept, a concept that swallows up every other concept:

Only for cases in which superficial resemblance is sufficient for falling under a concept will such an account [that is, a family resemblance account] work. It clearly won't work for natural kind concepts, like gold or man, and it won't work for concepts of intentional activity (e.g., playing versus working), and it won't work for functional concepts (something can resemble a heart perceptually and not be a heart), and it won't work for social concepts (someone can be dressed up as a judge and not be a judge), and so on and so forth. In general, it is not sufficient for being an $F$ that an objects looks like an $F$. As I noted earlier, it is not even sufficient for being in the same family that two people bear a family resemblance to each other-someone can have my nose and gait and not be genetically related to me. Having a family resemblance to paradigms is hardly ever sufficient for falling under a given concept (except the concept of family resemblance itself). There is a distinct danger that on Wittgenstein's picture there will turn out to be only one concept and everything falls under it-because everything bears some sort of resemblance to everything else, especially if we allow (as Wittgenstein does) intermediate links in the chain of resemblance. Concepts need discontinuities, and family resemblance is all continuity. (McGinn 2012, 29-30)

I find McGinn's (and Suits's) criticism of Wittgenstein's general idea of family resemblance concepts persuasive. First, while the analysis of the concept of a game defended by Suits (and McGinn) and the necessary conditions for being a game proposed by McGinn are quite abstract, they seem adequate to me. As I see it, Suits does succeed in elucidating the concept of a game. Secondly, I find the claim quite persuasive, that the idea of family resemblance is too permissive and possibly also incoherent. As McGinn says in the quotation above, "everything bears some sort of resemblance to everything else," and this does seem to mean that if we start out with an arbitrary concept, $C$, we will be able to think of pretty much every object (or property) as an instance of $C$. Clearly, this is not what we want.

${ }^{13}$ McGinn (ibid., 24) quotes Suits's analysis of the concept of a game: "To play a game is to attempt to achieve a specific state of affairs [perlusory goal], using only means permitted by the rules, where the rules prohibit use of more efficient in favor of less efficient means [constitutive rules], and where the rules are accepted just because they make possible such activity [lusory attitude]." See also Suits $(2014)$. Schauer $(2015,38)$ is aware of Suits's analysis, however, but rejects it on the grounds that even if it were correct (which Schauer doubts), "it may well be ... offered at such a high level of abstraction as to be essentially uninformative." 
I now want to turn to a consideration of two questions that specifically concern the concept of law. First, is the concept of law really a family resemblance concept? Secondly, assuming that it is indeed a family resemblance concept, what follows for those who wish to inquire into the nature of law? Beginning with the first question, I must say that I very much doubt that the concept of law is a family resemblance concept, and Schauer does not expend much energy showing that it is. Let us therefore consider this question, and let us begin by taking a look at some Western national legal orders, such as Swedish law, Italian law, American law, Australian law, Israeli law, etc. Do these legal orders have any property or properties in common, or are they related to each other only in the way of family resemblance? It seems to me that they do have several properties in common. Let me explain.

I shall say that law in its ideal-typical form (i) is a relation between a legal system and a legal organization, that a legal system (ii) is a system of norms, not just a set, and that its norms (iii) can be traced back to certain sources that can be handled on the basis of factual considerations, that a legal organization (iv) is constituted and regulated by the norms of the legal system, and (v) that its task is to interpret and apply said norms, and perhaps also to create some of them. Moreover, I shall say that law thus conceived (vi) aspires to regulate social life in general, and that it is (vii) non-optional, (viii) coercive, and (ix) claims to trump competing normative systems. ${ }^{14}$

I believe the above-mentioned national legal orders meet all or almost all of the conditions (i)-(ix). And I am pretty sure that the answer would be more or less the same if we were to include in our discussion non-Western national legal orders, such as Russian law, Japanese law, South Korean law, Indian law, or SaudiArabian law. Thus I conclude that all the central instances of law-national legal orders-share a number of properties, and that it is therefore a mistake to say that the concept of law is a family resemblance concept.

We are not finished yet, however. We should also consider EU law, international law, and perhaps even so-called transnational law (in the shape of the lex mercatoria or the lex sportiva). Do these instances of law have any one property or properties in common, or do they relate to one another only in the way of family resemblance?

It seems to me that they do have several properties in common. To begin with, it is quite clear that EU law can be seen as (i) a relation between a legal system and a legal organization, that its legal system (ii) is a system of norms, not just a set, and (iii) that its norms can be traced back to certain sources that can be handled on the basis of factual considerations, (iv) that the legal organization is constituted and regulated by the norms of the legal system, and (v) that its task is to interpret and apply said norms, and perhaps also to create some of them. I also believe it is fair to say that EU law (vi) aspires to regulate social life in general, and that it is (vii)

14 To be sure, the idea of introducing the concept of an ideal-type in the discussion is typically to avoid speaking of necessary and sufficient conditions for the applicability of the relevant concept. But the important point here is not to do that, but simply to identify some properties that many, perhaps all, instances of law share. To appreciate this, the reader need not believe that the method of the ideal-type is acceptable. 
non-optional, (viii) coercive, and (ix) claims to trump competing normative systems. $^{15}$

While international law can perhaps not be seen as a relation between a legal system and a legal organization, and while it does not seem to be coercive, it does appear to be (ii) a system of norms, not just a set, (iii) whose norms can be traced back to certain sources that can be handled on the basis of factual considerations. And it also appears to be (iv) non-optional and to (v) claim to trump competing normative systems.

The case of transnational law, finally, is more problematic, but it seems to me that it does share at least some of the above-mentioned properties with national law, EU law, and international law. But what is transnational law? I shall say that it differs from international law, in that it does not in any way owe its existence to nation states or concern the relations between nation states or between nation states and various organizations, but rather includes, as Jessup $(1956,2)$ puts it, "all law which regulates actions or events that transcend national frontiers." This means that transnational law is non-state law that regulates cross-border activities, such as business transactions between corporations or individuals that belong in different nation states and, more generally, actions and events that involve the crossing of national borders.

The two best-known examples of transnational law are the lex mercatoria and the lex sportiva. Those who claim that there is a transnational (or global) sports law, a lex sportiva, have in mind a system of norms that aims to regulate sports on the transnational (or global) level, a system whose norms were in most cases created by a legislature of sorts, namely the Olympic Committee, and are interpreted and applied by various law-applying organs, with the Court of Arbitration for Sports (CAS) in Lausanne, Switzerland at the top of the hierarchy. Ken Foster offers the following provisional characterization of global sports law (lex sportiva):

Global sports law [...] may provisionally be defined as a transnational autonomous legal order created by the private global institutions that govern international sport. Its chief characteristics are first that it is a contractual order, with its binding force coming from agreements to submit to the authority and jurisdiction of international sporting federations, and second that it is not governed by national legal systems. It would be in Teubner's phrase truly a 'global law without a state.' It is a sui generis set of principles created from transnational legal norms generated by the rules, and the interpretation thereof, of international sporting federations. This is a separate legal order that is globally autonomous. (Foster 2012,37)

So unlike the better-known lex mercatoria, the lex sportiva can be said to be a relation between a legal system and a legal organization, and its norms can indeed be traced back to a limited number of sources that can be handled on the basis of factual considerations. Moreover, while the lex sportiva, like the lex mercatoria, does not aspire to regulate social life in general, it is, unlike the lex mercatoria, non-optional and coercive, and it also claims to trump competing normative systems.

${ }^{15}$ One might, of course, wonder if it is really true that EU law aspires to regulate social life in general, since it is primarily a matter of administrative law, not private law or penal law, and since most of its norms do not apply directly to the citizens in the various member states. But nothing much will depend in this context on whether EU law meets criterion (vi) or not. 
On the basis of this rather brief consideration of our most familiar instances of law, I conclude that it is a mistake to think of the concept of law as a family resemblance concept. As far as I can see, the fact of the matter is that national law, EU law, international law, and even transnational law in the shape of lex sportiva share a number of properties.

The question of whether the existence of some of these shared properties is also a necessary condition for the applicability of the concept of law is a further question, which I shall not pursue here. As I see it, the logical relation between being a shared property of the above-mentioned instances of law and being a property that corresponds to a necessary condition for the applicability of the concept of law is as follows: If the existence of a property, $p$, is necessary for the applicability of the concept of law, then all instances of law have (and must have) $p$-if they did not, they would not be instances of law. However, even if all instances of law have $p$, the existence of $p$ may not be a necessary condition for the applicability of the concept of law. That is to say, being a property that is shared by all instances of law is a necessary, but not a sufficient, condition for being a property the existence of which is necessary for the applicability of the concept of law.

\section{Anti-Essentialism and Legal Thinking}

Let us now assume, for the sake of argument, that Schauer is right, so that not even all the central instances of law share any property or properties, where the properties in question are such that if they were present, they would distinguish law from non-law. If we do, what follows? As far as I can see, confused legal thinking is what follows. To illustrate the difficulties I have in mind, I should like to consider Schauer's discussion of the cultural contingency of obedience to law (Schauer 2015, 73-4). Observing that the willingness on the part of the citizens to obey the law varies quite a bit from one country to another, Schauer points out that these variations may become quite important, if we think of the prevalence of puzzled persons as an empirical fact, on the basis of which we construct our theories of law. He reasons convincingly that a theory of law that ignores coercion, on the grounds that there are many puzzled persons around, may turn out to be adequate precisely in places where there are many puzzled persons around, but not elsewhere, and this in turn is to say (though Schauer does not say so) that such a theory will likely not qualify as a theory of (the nature of) law-for it will not apply to law everywhere, but only to law in those places where there are sufficiently many puzzled persons.

So far so good. But Schauer also says that this may not be much of a problem, because we have no good reason to think of law in culture-independent terms. He argues (p. 74), more specifically, that we have no reason to believe that law has a cross-cultural essence and points out that the word "law" may be nothing more than a label attached to "a diverse collection of socio-governmental phenomena neither joined by shared properties nor interestingly connected across different systems." This is, of course, very much in keeping with his anti-essentialism.

I find this stance problematic, however. For it seems to me that if "law" is used to refer to entities that have little or nothing in common, the question will sooner or later arise as to why we as jurisprudents or legal scholars should be interested in thinking of these entities as instances of law at all or, for that matter, as instances of anything. For 
example, why should Americans want to translate, say, a German term, "Recht," as law in the first place, if they did not think that Recht had some interesting properties in common with law? To say that Americans have one concept of law, $A C L$, and that Germans have another, GCL, would not be an interesting claim, unless one also assumed that $A C L$ and GCL are in some sense different interpretations (conceptions, as Dworkin 1978, 134-6, says) of a common, more fundamental concept of law, $C C L$-if they were not, it would not be very interesting to maintain that Americans and Germans have different concepts of law. Indeed, it would not be clear what we meant by insisting that they have different concepts of law.

Schauer would probably respond to this objection that it misrepresents the situation, that the reality of the situation is not that the Americans have one concept of law and the Germans another, but that they have the same concept of law, namely, a family resemblance concept of law. ${ }^{16}$ His position, as we have seen, is that while not all instances, not even all the central instances, of the (family resemblance) concept of law share any property or properties, they are related to one another in the family resemblance way. This would mean, from the point of view of a given family resemblance concept of law, that although German Recht and American law might not have any one property or properties in common, German Recht may have one or two properties in common with French droit, say, which may have one or two properties in common with Italian diritto, which may have one or two properties in common with Swedish rätt, say, which may have one or two properties in common with American law, or perhaps no property at all in common with American law, or something along those lines. But if this is all the likeness there is between American law and German Recht, why expect that the Americans would learn anything of interest concerning American law-obedience from the German experience of Recht-obedience? If American law and German Recht have no properties in common-not even the seemingly fundamental property of being sets or systems of norms-why should anybody be interested in comparing them? For example, why should scholars of comparative law wish to investigate similarities and differences between, say, German, French, and Canadian law on bankruptcy, or marriage, or race discrimination, if they did not also assume that bankruptcy, or marriage, or race discrimination, was, roughly speaking, the same thing in France, Germany, and Canada?

Since this is so, it is not surprising that a central assumption on the part of any jurisprudent will almost certainly be that it is possible to analyze the concept of law in terms of necessary and sufficient conditions. Indeed, it seems to me that if the theorist did not make this assumption, his interest in the question of the nature of law would lack any real point or purpose. Julie Dickson, who follows Raz, and who also speaks of "essential" properties of law, puts it as follows:

The approach [to an inquiry into the nature of law] just set out does not claim that legal systems are necessary features of all human societies, nor that all human societies have thought of law in the same way. The point is merely this: given that we regard there as being something special about certain forms of social organization which we account as legal and given that we recognize that, throughout history, some forms of social organization have amounted

${ }^{16}$ He might, of course, reason that they have two different concepts, ACL and GCL, each of which, or one of which, is a family resemblance concept. But if so, what would the relation be between ACL or GCL? 
to legal systems and some have not, the only way in which we can begin to investigate what this particular form of social organization is like, and how it differs from other types of social organization, is by attempting to isolate and explain those features which are constitutive of it, and which make it into what it is. Such features can be nothing more nor less than law's essential properties, and it will be necessarily true that law exhibits such properties. (Dickson 2001, 19. Footnote omitted. $)^{17}$

It therefore seems to me that if we suspected that Schauer's legal anti-essentialism was an adequate description of the world of law, as Schauer thinks it is, we should ask ourselves whether it would not be better to forget about law thus conceived and try instead to distinguish a group of instances of law that did share some properties, properties that we might then speak of as being necessary properties of law. If we were unable to do this, we might as well give up the game, or so it seems to me.

\section{Family Resemblance and Central Instances of a Concept}

Schauer adduces, as we have seen, two arguments in support of the claim (MMC), namely, (1a) that people in general think of concepts not in terms of necessary and sufficient conditions for their proper application, but in terms of central and peripheral instances, and accept that not all instances, not even all the central instances, of a concept share any one property or properties, and (1b) that the concept of law is a family resemblance concept, or a cluster concept. I am now going to argue that claims (1a) and (1b) contradict one another.

The problem is that it seems difficult to square the existence of central instances of a concept, $C$, which is assumed in (1a), with the idea that $C$ is a family resemblance concept (or a cluster concept), which is asserted in (1b). For, as we have seen, if $C$ is a family resemblance concept (or a cluster concept), not even all the central instances of $C$ share any one property. But if this is so, what makes a central instance of $C$ a central instance? In my view, it is natural to reason that a central instance of $C$ is precisely an instance that has all or most of the properties that are shared by the various instances of $C$, and that a peripheral instance of $C$ is precisely an instance that has only a few of those properties. However, this explanation is not available when the instances in question do not share any property at all.

To be sure, one could argue that a central instance of a concept is an instance that occurs more frequently, or is in some other way more salient in the everyday experience of the concept-users, than a peripheral instance. I am not, however, sure that this would be a good idea. Not only would it involve changing the intuitive meaning of "central instance of a concept," but the existence of central instances of a concept would depend, on this analysis, very much on the circumstances, which may change, so that the determination would vary with changing circumstances.

If I am right about this, the two claims adduced by Schauer in support of the anti-essentialist thesis, namely, (1a) and (1b), could not be true together, and this means that he needs to abandon either the one claim or the other. This may not be a big problem, however. For whereas (1a) is either irrelevant (on the first interpretation) or incomplete (on the second and the third interpretations), (1b) is false in

17 Dickson, who appears to be concerned with necessary (and sufficient) conditions for the applicability of the concept of law, points out (as I understand her) that she is not a legal essentialist (ibid., 19). 
that it just does not apply to the concept of law. So, in my view, Schauer's best bet is to choose (1a) and focus on the second interpretation, according to which the way people in general think of and with concepts constitutes (or determines) the existence and properties of concepts, or on the third interpretation, according to which the best explanation of the fact (if it is a fact) that people in general think of and with concepts in the way described is that concepts are best understood in terms of central and peripheral instances.

\section{Explication and Ideal-Type Analysis}

I have considered and rejected two of Schauer's three claims in support of (MMC), namely claims (1a) and (1b). I have not, however, rejected (MMC), because I am inclined to accept claim (2) and because (as I have said) I find the method of philosophical analysis, conceived as conceptual analysis, somewhat problematic, albeit mainly for other reasons than the ones Schauer points to. How, then, should the jurisprudent proceed, if he is nevertheless interested in the question of the nature of law, or some such question? Well, it seems reasonable to consider alternative methods of jurisprudential inquiry. Let me briefly discuss two such methods.

I have said that I think of the inquiry into the nature of law as a matter of analyzing the concept of law and that I think of the concept of law as (at least part of) the meaning of the term "law." I am not convinced, however, that an analysis or elucidation of a concept has to be conceived as an attempt at making clear the one true import of the concept in light of the analyst's intuitions, as the above-mentioned method of philosophical analysis has it. As I see it, legal concepts do not usually have a sufficiently precise import to make such an enterprise meaningful. Following Georg Henrik von Wright, I prefer instead to see the analysis of legal concepts as a matter of molding or specifying their import in a fruitful way:

Philosophic reflection on the grounds for calling a thing ' $x$ ' is challenged in situations, when the grounds have not been fixed, when there is no settled opinion as to what the grounds are. The concept still remains to be moulded and therewith its logical connexions with other concepts to be established. The words and expressions, the use of which bewilder the philosopher, are so to speak in search of a meaning.

I would not wish to maintain that the only fruitful way of dealing with the problems here is to mould the unmoulded meanings, to make fixed and sharp that which ordinary usage leaves loose and undetermined. It has seemed to me, however, that conceptual inquiries, which take the form of a moulding or shaping of concepts, are particularly suited for the treatment of problems in ethics and some related branches of philosophy (aesthetics, political philosophy). (Von Wright 1963, 5)

One might, in keeping with this, employ the method of explication, which is similar to, but nevertheless different from, the method of conceptual analysis (see Carnap 1950, 3-8; Frändberg 2005, 94-6; Gupta 2014, 7-9; Spaak 1994, 34-6; Spaak 2009a; Wedberg 1951, 250-2). To explicate a concept is to refine the concept in order to make it more useful for a certain purpose and, if possible, to do this within the framework of a reasonably fruitful theory, in my case legal positivism. To judge the adequacy of the explicatum (that which does the explicating) in relation to the explicandum (that which is to be explicated), one will have to consider (i) the relation of similarity between the explicatum and the explicandum, as well as (ii) the exactness, (iii) the fruitfulness, and (iv) the simplicity of the explicatum. That is to 
say, one wants the explicatum to be similar to the explicandum, but more exact, as well as fruitful, and simple. If these conditions are satisfied, the explication will be adequate. This means, of course, that an explication will not be true or false, but rather more or less adequate in light of a given purpose, and this in turn means that one needs to be clear about the purpose of explicating the concept in question. ${ }^{18}$

In my view, the method of explication suits legal analysis well. Since law is (in my view, at least) a human creation, a broadly instrumental approach to questions of legal analysis will often, but perhaps not always, be advisable. ${ }^{19}$ One difficulty with the method of explication as applied to the concept of law itself, however, is that it is rather difficult to think of a reasonably determinate purpose of such an explication. What I have in mind is that the concept of law, unlike, say, the concept of a legal right or the concept of legal competence (power), ${ }^{20}$ does not seem to play an important role in ordinary, first-order legal thinking; ${ }^{21}$ and this means that one cannot reasonably maintain that the purpose of the explication is to fashion a concept of law that will be fruitful in such legal thinking, either in general or in some more specific context. And since I find it difficult to think of another convincing purpose of such an explication, I conclude that we have reason to consider the possibility of adopting an alternative method of inquiry, namely the so-called method of the ideal-type.

The method of the ideal-type was championed by Weber $(1949,89-111)$ and put to good use by thinkers such as Ross (1967, chap. 3), Hedenius (1977), and Finnis (1980, chap. 1). The idea is that the theorist is to elaborate an ideal-typical concept of $X$, in our case the concept of law, and proceed to locate the relevant real phenomenon or phenomena along the dimensions of the ideal-type, in order to gain a better understanding of it (or them) and perhaps also of its (or their) relation to other phenomena of the same general type. As Weber puts it,

[a]n ideal type is formed by the one-sided accentuation of one or more points of view and by its synthesis of a great many diffuse, discrete, more or less present, and occasionally absent concrete individual phenomena, which are arranged according to those one-sidedly emphasized viewpoints into a unified analytical construct (Gedankenbild). In its conceptual purity, this mental construct (Gedankenbild) cannot be found empirically anywhere in reality. It is a utopia. Historical research faces the task of determining in each individual case, the extent to which this ideal-construct approximates to or diverges from reality, to what extent for example, the economic structure of a certain city is to be classified as a "city-economy." (Weber 1949, 90)

${ }^{18}$ Note that the purpose of the explication of the concept of $X$ is not necessarily the same as the purpose of $X$, or even the purpose of the concept of $X$, if there is one. Although it is, to be sure, difficult to think of a reasonably determinate purpose (or function) of law itself (on this, see, e.g., Hart 1994, 249), that is not the main problem in this context.

19 For an interesting discussion of the dangers of instrumentalist thinking in law, especially the threat it poses to the ideal of the rule of law, see Tamanaha (2006).

${ }^{20}$ I have elsewhere explicated the concept of legal competence (or legal power). In doing that I said that the purpose of the explication was to fashion a competence concept that we could use to discuss questions concerning legal validity or invalidity in an adequate way (Spaak 1994, 21).

${ }^{21}$ Ross $(1959,11)$ seems to believe that the concept of law does play a role in first-order legal thinking, albeit indirectly, because he reasons that one must (rationally) presuppose it when one maintains, say, that the speed limit in the city of Copenhagen is 50 kilometers per hour. But even if Ross is right, the theorist will not get much guidance in his efforts to explicate the concept of law from such an indirect use of the concept of law in legal thinking. 
Ross (1967), for example, who is concerned with the concept of democracy, operates with three dimensions of the ideal-type, proposing that the ideal-type of democracy is such (i) that all citizens have the right to vote, (ii) that they have maximal control over their elected representatives, and (iii) that they can vote about every possible subject matter. Hedenius $(1977,147-9)$, who is concerned with the concept of ownership, operates with two dimensions of the ideal, proposing that the ideal-type of ownership is such (i) that the owner has maximal protection of possession and (ii) maximal possibilities to use the object. Note that the ideal-type is not necessarily a moral or political ideal (Weber 1949, 91-2). The idea is by no means to say that, for example, democracy in its Rossian ideal-typical form is a moral or political ideal.

The method of the ideal-type is especially appropriate in cases where the theorist has doubts about the possibility of finding (or stipulating) sufficient and necessary conditions for something, $X$, to qualify as something else, $L$. For example, if one thinks (or suspects) that $L$ is something that comes in degrees, and that therefore it will be futile to assume that for every $X, X$ is $L$ or $X$ is not $L$, one will also doubt the possibility of specifying necessary and sufficient conditions for $X$ to qualify as L. On Lon Fuller's analysis of the concept of law (Fuller 1969, chap. 2), for example, the existence of law will likely turn out to be a matter of degree, because the conformity of any purported legal order to Fuller's eight principles (which constitute the so-called inner morality of law) will likely be a matter of degree. I should, however, add that, strictly speaking, the fact that $L$ comes in degrees does not make it impossible to analyze $X$ in terms of necessary and sufficient conditions, though it does mean that the relevant conditions will be somewhat imprecise.

If the jurisprudent were to adopt the method of the ideal-type in his inquiry into the nature of law, he would have to begin by describing law in its ideal-typical form and proceed to compare real instances of law-national law, international law, EU law, transnational law, etc.-with the ideal-type of law, like I did (very briefly) above in Section 6. Clearly, one very interesting question is whether law in its ideal-typical form is coercive. As is clear from my brief discussion in Section 6, I am inclined to answer this question in the affirmative.

I have to admit, however, that I can see no fool-proof way of determining what, exactly, law in its ideal-typical form is, and this is not surprising in light of Weber's observation that it makes no sense to maintain that a given ideal-type (of law, of capitalism, of Christianity, etc.) is true or false, correct or incorrect. As Weber explains, the point of introducing the concept of an ideal-type into social science was to account for the fact that social-scientific work will inevitably depend on value judgments on the part of the social scientist about what features of a phenomenon are of interest and should be highlighted. Thus, discussing the idea of capitalistic culture, he states the following:

It is possible, or rather, it must be accepted as certain that numerous, indeed a very great many, utopias of this sort can be worked out, of which none is like another, and none of which can be observed in empirical reality as an actually existing economic system, but each of which however claims that it is a representation of the "idea" of capitalistic culture. Each of these can claim to be a representation of the "idea" of capitalistic culture to the extent that it has really taken certain traits, meaningful in their essential features, from the empirical reality of our culture and brought them together in a unified ideal-construct. For those phenomena which interest us as cultural phenomena are interesting to us with respect to very different kinds of evaluative ideas to which we relate them. Inasmuch as the "points of view" 
from which they can become significant for us are very diverse, the most varied criteria can be applied to the selection of the traits which are to enter into the construction of an idealtypical view of a particular culture. (Weber 1949, 91)

We see, then, that the method of the ideal-type will inevitably involve value judgments on the part of the social scientist (or the legal scholar) in much the same way as the above-mentioned method of explication does, and this means, of course, that the jurisprudent who worries about how to determine the purpose of his explication of the concept of law will not be able to avoid the general problem of justifying the choice of one point of view, or value, over another by adopting instead the method of the ideal-type.

\section{A Possible Contradiction}

Schauer treats the question of whether the citizens obey the law just because it is the law in Chapter 5, and the question of whether legal officials obey the law just because it is the law in Chapter 6, and he concludes that we have good reason to believe that there are very few persons around who obey the law just because it is the law. If he is right about this, as I think he is, one fairly weighty reason for focusing jurisprudential interest on the idea of non-coercive law, namely the above-mentioned argument (B), that there are many puzzled persons around, has dropped out of consideration (on this argument, see Section 2). And since he has already considered and rejected the other main argument in support of focusing jurisprudential interest on the idea of non-coercive law, namely argument (A), that we can conceive of law, including legal obligation, without coercion (on this argument, too, see Section 2), he concludes that we should no longer be concerned in our inquiry into the nature of law with essential properties of law, and that therefore the task of explaining how law differs from other social institutions or, more generally, from other social phenomena, invites consideration precisely of the ubiquitous occurrence of legal coercion.

He therefore turns in Chapter 11 to consider the question of the differentiation of law, as he refers to it, that is, the question of how law differs from other social institutions, or more generally, from other social phenomena. The label "differentiation of law," as Schauer uses it, is meant to convey the idea that we are concerned here not with (what he calls) the essential properties of law (for this would be a matter of "demarcation" in his terminology), but with properties that are typical of law and important. He considers in turn (what he calls) (i) law's sociological differentiation, (ii) law's procedural differentiation, (iii) law's methodological differentiation, and (iv) law's source differentiation, noting that they are all candidates for the differentiation of law (Schauer 2015, 155-7). He then adds that coercion, too, is a feature that may be of interest in this context (ibid., 158) and summarizes his views on the differentiation of law as follows:

Like many other aspects of law as we experience it, coercion is neither necessary nor sufficient for law. But legal coercion's contingent ubiquity testifies to the fact that in many domains there are valuable goals that cannot be achieved by cooperation alone, even the kind of cooperation in which people internalize second-order reasons suppressing their firstorder desires and decisions. If we ignore this fact we will have ignored something very important about why law exists and what functions it serves. [...] The coercive dimensions 
of law are not all of law, but if the task of understanding a phenomenon starts with certain features of the phenomenon whose presence any satisfactory explanation of the phenomenon must provide, then coercion must be numbered among those features. If a satisfactory account of law must, as Hart reminded us, "fit the facts," then law's coercive capacity and reality is one of the facts that such an account must fit. (Schauer 2015, 165)

Schauer also points out that an understanding of the role of coercion in law may be valuable not only because it amounts to knowledge of law, but also because it may be helpful in matters of institutional design. As he notes, law is good at some tasks and less good at others, and an important job for law-informed institutional design is to decide which tasks are appropriate for legal institutions and which tasks are appropriate for other social institutions (ibid., 168): "If we ignore or slight that capacity [the coercive capacity of law], or even if we think that exploring it is not part of a theoretical or philosophical enterprise, we may lose some of the understanding of law that helps us to see when using law is wise-and when it is not." What Schauer is saying, I take it, is that a broader understanding of what an inquiry into the nature of law is, which allows the jurisprudent to focus on the coercive aspect of law, even though coerciveness is not an essential property of law (in Schauer's sense), will very likely have considerable instrumental value. And I believe he is right.

Schauer's discussion of the differentiation of law is of particular interest in this context, since it appears to be in tension with, and might even undermine, the legal anti-essentialism that Schauer defends. Consider in this regard his focus on the properties of law of having (i) primary and secondary rules, (ii) a rule of recognition, and a (iii) a systemic character (Schauer 2015, 160). If we can understand the rules of the Mafia in terms of primary and secondary rules, a rule of recognition, and a system of rules, Schauer says, why not call it "law"? This might seem a sensible question, but there is a problem here. Given that Schauer's anti-essentialist position is that not even all the central instances of the concept of law share any one property or properties, including the above-mentioned properties (i)-(iii), why should the fact, if it is a fact, that the rules of the Mafia feature these properties tempt us to think of those rules as law in the first place? Could it be that Schauer forgets his anti-essentialism for a moment and takes it for granted that these properties are indeed shared by all instances, at least all central instances, of the concept of law and assumes as a matter of course that if they are shared (and possibly necessary) properties, then they are sufficient, too.

Consider also Schauer's claim (ibid., 161), that to say that there is non-state law is to say "that all of the features we typically or even universally see in the legal systems of modern nation-states are represented in vast numbers of associations, organizations, and institutions whose physical boundaries are not those of a nation-state and which may, sometimes but not necessarily, claim jurisdiction over only a limited number of activities." My impression is that Schauer is here again assuming the existence of precisely that which he says does not exist, namely, properties that are shared by at least all central instances of the concept of law. I mean, if "all of the features we typically or even universally see in legal systems of modern nation-states" are not properties shared by at least all central instances of the concept of law, what are they?

To be sure, Schauer has argued that not even all the central instances of the concept of law share any one property or properties, that there are no necessary 
conditions for the existence of law, not that there are no sufficient conditions. So he is not making a logical mistake in suggesting that while there are no shared properties even of the central instances of the concept of law, we may (or should) be tempted to think of the rules of the Mafia as law just because they feature certain widespread, though not universal, properties of law. Nevertheless, since he has not touched upon the question of sufficient conditions for the existence of law earlier in his book, one may well wonder why he now thinks it would be so natural to recognize the above-mentioned properties as being sufficient for the existence of law. But he could perhaps say with Colin McGinn (see Section 6 above) that, on his analysis, there is one, rather obvious sufficient condition for something, $X$, to qualify as law, namely that $X$ resembles in some respect one or more instances of the concept of law. And this condition would seem to be satisfied in the case of the rules of the Mafia.

I should like to point out in conclusion that the objection to Schauer's analysis that I have raised in this section is not very serious. If I am right that there is indeed a tension, perhaps even a contradiction, between Schauer's antiessentialism, on the one hand, and the claims about Mafia law and non-state law, on the other hand, Schauer could solve the problem simply by reformulating his claims about Mafia law and non-state law in more guarded terms.

\section{Law and Coercion-Schauer and Olivecrona}

As we have seen, Schauer points out already at the beginning of his book, that the conventional wisdom among contemporary jurisprudents in the English-speaking world is that it is not in the nature of law to be coercive, and that the prominent exception to the received view is Dworkin $(1986,188)$, who maintains that (what he refers to as) a conception of law "must explain how what it takes to be law provides a general justification for the exercise of coercive power by the state." While this is true enough, ${ }^{22}$ it is worth noting that we do not have to go all the way back to the time of Jeremy Bentham and John Austin to find a jurisprudent who puts coercion at the center of law. For Scandinavian realist Karl Olivecrona, who was active from the late 1920's to the late 1970's, maintains in the first edition of Law as Fact (Olivecrona 1939) precisely that coercion is at the center of law. ${ }^{23}$

Olivecrona, who speaks of "force" and takes "force" to cover not only "actual violence," but also "the influence exercised by the concentration of superior strength" (ibid., 126), maintains (i) that (organized) force is necessary to the existence of law; (ii) that law consists chiefly of rules about the use of force; (iii) that the force of law exerts its influence on social life chiefly indirectly; (iv) that the force of law causes the citizens to internalize the moral values and standards that

22 It turns out that Dworkin does not have much to say about legal coercion.

${ }^{23}$ It is worth noting in this context that both Hans Kelsen and Alf Ross, who were contemporaries with Olivecrona, consider national law to be in its essence a coercive apparatus. As Kelsen $(1999,19)$ puts it, the word 'law' refers to a "specific social technique of a coercive order," namely, "the social technique which consists in bringing about the desired social conduct of men through the threat of a measure of coercion which is to be applied in the case of a contrary conduct." And Ross $(1959,34)$, for his part, holds that "[a] national law system is the rules for the establishment and functioning of the State machinery of force." Schauer $(2015,21)$ does mention Kelsen. 
make up the content of the legal rules; and (v) that abolishing the force of law would likely result in important-and dangerous-changes in the moral values and standards we accept. He also maintains (vi) that organized force can serve the citizens only if there is an organization, namely the state, that has the monopoly on power in the relevant territory, (vii) that the Marxist theory of the state, according to which law and state will ultimately wither away, is mistaken, and (viii) that a belief in international law and the rights and duties involved is apt to lead to increased use of violence. In his later writings, he reiterates claims (i), (ii), and (vi), but does not have much to say about claims (iii)—(v), (vii), and (viii). He does, however, add in his later writings (ix) that the coercive power of the state presupposes that the state also has psychological power, and vice versa, and $(x)$ that only judicial independence and a sound judicial ethics can guarantee legal certainty. (For more on Olivecrona on coercion, see Spaak 2014, chap. 10)

The fact that Schauer does not at all consider the same questions as Olivecrona does is of some interest in light of the fact that both Schauer and Olivecrona purport to be concerned precisely with the question of the nature of law. But whereas Schauer, as we have seen, is explicit that he believes that an inquiry into the nature of law should not be a search for essential properties of law, but should focus instead on properties that are typical of law and important, Olivecrona did not at all consider the question of what an inquiry into the nature of law is (or should be). Indeed, I do not think Olivecrona realized that there was an issue to be dealt with here. In any case, whereas Schauer rejects the very idea that law has necessary properties, Olivecrona appears to have assumed that law does have necessary properties, though he did not distinguish carefully between conceptual (or logical) necessity and "natural" necessity. ${ }^{24}$ My impression is that it is precisely Schauer's more capacious understanding of what an inquiry into the nature of law is that explains the difference between Schauer's and Olivecrona's claims about law and coercion.

I conclude that neither of the two most prominent contemporary jurisprudents to offer an in-depth philosophical treatment of the question of the relation between law and coercion, has accepted, or acted on, the view that an inquiry into the nature of law is to be understood as a search for essential properties of law (in the sense outlined and discussed by Schauer in his book). The reason is not far to seek: If they had accepted this more demanding conception of what an inquiry into the nature of law is, they could not consistently with their own meta-philosophy have treated the topic jurisprudentially, that is, as part of an inquiry into the nature of law. They could not have done this, because (as Schauer points out), coercion simply is not a conceptually (or metaphysically) necessary feature of law. Of course, as I have pointed out (in Section 2), they could have treated the topic philosophically, but with no pretension to tell us anything about the nature of law; and this would, in my view, have been good enough.

${ }^{24}$ I have in mind here the distinction that Hart $(1958,621-4)$ draws in his discussion of the relation between law and morals. He points out that given that the world, including ourselves, is what it is, and given that we wish to survive together with other human beings, rules about property and rules that prohibit the free use of violence do seem to be "naturally," though not conceptually, necessary parts of any legal system. 
Department of Law

Stockholm University

SE-16191 Stockholm

Sweden

E-mail: Torben.Spaak@juridicum.su.se

\section{References}

Alexy, R. 2002. The Argument from Injustice. A Reply to Legal Positivism. Trans. S. L. Paulson and B. Litschewski Paulson. Oxford: Oxford University Press.

Alexy, R. 2008. On the Concept and Nature of Law. Ratio Juris 21: 281-99.

Åqvist, L. 1962. Comments on the Paradox of Analysis. Inquiry 5: 260-4.

Bulygin, E. 1993. Alexy und das Richtigkeitsargument. In Rechtsnorm und Rechtswirklichkeit. Festschrift für Werner Krawietz zum 60. Geburtstag. Ed. A. Aarnio et al., 19-25. Berlin: Duncker and Humblot.

Bulygin, E. 2000. Alexy's Thesis of the Necessary Connection between Law and Morality. Ratio Juris 13:133-7.

Carnap, R. 1950. The Logical Foundations of Probability. Chicago, IL: The University of Chicago Press.

Carnap, R. 1956. Meaning and Necessity. A Study in Semantics and Modal Logic. Chicago, IL: Phoenix Books.

Coleman, J. and O. Simchen. 2003. Law. Legal Theory 9: 1-41.

DePaul, M. R. and W. Ramsey, eds. 1998. Rethinking Intuition. The Psychology of Intuition and Its Role in Philosophical Inquiry. Boston, MA: Rowman and Littlefield Publishers.

Dickson, J. 2001. Evaluation and Legal Theory. Oxford: Hart.

Dworkin, R. 1978. Taking Rights Seriously. London: Duckworth.

Dworkin, R. 1986. Law's Empire. Cambridge, MA, and London: Belknap.

Finnis, J. 1980. Natural Law and Natural Rights. Oxford: Clarendon.

Foster, K. 2012. Is there a Global Sports Law? In Lex sportiva: What is Sports Law? Ed. R. C. R. Siekmann and J. Soeks, 35-52. The Hague: Springer.

Frändberg, A. 2005. An Essay on the Systematics of Legal Concepts. In A. Frändberg, Rättsordningens idé, 63-96. Uppsala: Iustus.

Frege, G. 1980. On Sense and Meaning. In Translations from the Philosophical Writings of Gottlob Frege. Ed. P. Geach and M. Black, 56-78. Totowa, NJ: Barnes and Noble.

Fuller, L. L. 1969. The Morality of Law. New Haven, CT, and London: Yale University Press.

Grice, H. P. and P. F. Strawson. 1956. In Defense of a Dogma. Philosophical Review 65: $141-58$.

Gupta, A. 2014. Definitions. In Stanford Encyclopedia of Philosophy. Stanford University, Fall 2014. http://plato.stanford.edu/archives/fall2014/entries/ definitions /

Harman, G. 1999. Doubts About Conceptual Analysis. In G. Harman, Reasoning, Meaning and Mind, 138-43. Oxford: Oxford University Press.

Hart, H. L. A. 1958. Positivism and the Separation of Law and Morals. Harvard Law Review 71: 593-629.

Hart, H. L. A. 1961. The Concept of Law. Oxford: Clarendon.

Hart, H. L. A. 1994. The Concept of Law. Ed. P. Bulloch and J. Raz. Oxford: Oxford University Press. 
Hedenius, I. 1977. Äganderättsbegreppet (The Concept of Ownership). In I. Hedenius, Filosofien $i$ ett foränderligt samhälle (Philosophy in a Changing Society), 13055. Stockholm: Bonniers.

Jackson, F. 1998. From Metaphysics to Ethics. A Defence of Conceptual Analysis. Oxford: Oxford University Press.

Jessup, P. 1956. Transnational Law. New Haven, CT: Yale University Press.

Kelsen, H. 1999. General Theory of Law and State. Trans. A. Wedberg. Union, NJ: The Lawbook Exchange. (1st ed. 1945).

Langford, C. H. 1942. The Notion of Analysis in Moore's Philosophy. In The Philosophy of G. E. Moore. Ed. P. A. Schilpp, 319-42. Evanston and Chicago, IL: Northwestern University Press.

Leiter, B. 2007. Naturalizing Jurisprudence. Oxford: Oxford University Press.

Lowe, E. J. 2002. A Survey of Metaphysics. Oxford: Oxford University Press.

Margolis, E. and S. Laurence. 2014. Concepts. In Stanford Encyclopedia of Philosophy. Stanford University, 2014. http://plato.stanford.edu/archives/spr2014/ entries/concepts/

McGinn, C. 2012. Truth by Analysis. Games, Names, and Philosophy. Oxford: Oxford University Press.

Miller, A. 2007. Philosophy of Language. An Introduction. London and New York: Routledge.

Moore, G. E. 1942. A Reply to My Critics. In The Philosophy of G. E. Moore. Ed. P. A. Schilpp, 660-7. Evanston, IL: Northwestern University Press.

Moore, M. S. 2000. Educating Oneself in Public. Critical Essays in Jurisprudence. Oxford: Oxford University Press.

Oberdiek, H. 1976. The Role of Sanctions and Coercion in Understanding Law and Legal Systems. The American Journal of Jurisprudence 21: 76-94.

Olivecrona, K. 1939. Law as Fact. Copenhagen: Einar Munksgaard and London: Humphrey Milford.

Platts, M. 1997. Ways of Meaning. Cambridge, MA: MIT Press.

Quine, W. V. O. 1953. Two Dogmas of Empiricism. In W. V. O. Quine, From a Logical Point of View, 20-46. Cambridge, MA: Harvard University Press.

Radbruch, G. 2006. Statutory Lawlessness and Supra-Statutory Law. Transl. B. Litchewski Paulson and S. L. Paulson. Oxford Journal of Legal Studies 26: 1-11. (Originally published in German as Radbruch, G. 1946. Gesetzliches Unrecht und Übergesetzliches Recht. Süddeutsche Juristen-Zeitung 1: 105-8.)

Raz, J. 1990. Practical Reason and Norms. Princeton, NJ: Princeton University Press.

Raz, J. 2009. Can There Be a Theory of Law? In J. Raz, Between Authority and Interpretation, 17-46. Oxford: Oxford University Press. (Originally published in 1985, The Blackwell Guide to the Philosophy of Law and Legal Theory. Ed. M. P. Golding and W. A. Edmundson, 324-42. Oxford: Blackwell.)

Robinson, R. 1954. Definition. Oxford: Clarendon.

Ross, A. 1959. On Law and Justice. Berkeley and Los Angeles, CA: University of California Press.

Ross, A. 1967. Varför demokrati? [Why Democracy?]. Transl. A. Degerman. Stockholm: Tiden.

Schauer, F. 2015. The Force of Law. Cambridge, MA. Harvard University Press.

Searle, J. R. 1969. Speech Acts. Cambridge: Cambridge University Press.

Smith, M. 1994. The Moral Problem. Oxford: Blackwell.

Sosa, E. 1983. Classical Analysis. The Journal of Philosophy 80: 695-710.

Spaak, T. 1994. The Concept of Legal Competence. Dartmouth: Dartmouth Publishers. 
Spaak, T. 2009a. Explicating the Concept of Legal Competence. In Concepts in Law.

Ed. J. C. Hage and D. von der Pfordten, 67-80. Dordrecht: Springer.

Spaak, T. 2009b. Meta-Ethics and Legal Theory: The Case of Gustav Radbruch. Law and Philosophy 28: 261-90.

Spaak, T. 2014. A Critical Appraisal of Karl Olivecrona's Legal Philosophy. Heidelberg and Dordrecht: Springer.

Strawson, P. F. 1992. Analysis and Metaphysics. Oxford: Oxford University Press.

Suits, B. 2014. The Grasshopper. Games, Life, and Utopia. Ontario: Broadview.

Tamanaha, B. Z. 2006. Law as a Means to an End. Threat to the Rule of Law. Cambridge: Cambridge University Press.

Von Wright, G. H. 1963. The Varieties of Goodness. London and New York: Routledge and Kegan Paul.

Weber, M. 1949. "Objectivity" in Social Science and Social Policy. In M. Weber, The Methodology of the Social Sciences. Ed. and transl. E. A. Shils and H. A. Finch, 49-112. New York: The Free Press. (1st ed. 1904.)

Wedberg, A. 1951. Some Problems in the Logical Analysis of Legal Science. Theoria 17: $246-75$.

Wittgenstein, L. 1960. The Blue and Brown Books. New York: Harper and Row.

Wittgenstein, L. 1968. Philosophical Investigations. Ed. G. E. M. Anscombe and R. Rhees, transl. G. E. M. Anscombe. New York: Macmillan.

Zweigert, K. and H. Kötz. 1998. An Introduction to Comparative Law. Transl. T. Weir. Oxford: Oxford University Press. 